Kong. Res. J. 2(2) : 143-145, 2015

ISSN 2349-2694

Kongunadu Arts and Science College, Coimbatore.

\title{
ANTIBACTERIAL ACTIVITY OF EARTHWORMS' COELOMIC FLUID
}

\author{
Kathireswari, $\mathrm{P}^{*}$. \\ PG and Research Department of Zoology, Kongunadu Arts and Science College, Coimbatore \\ *E.mail: kathireswari@gmail.com
}

\begin{abstract}
This study was carried out with an objective to investigate the antibacterial potentials of earthworm coelomic fluid. The aim of the study is to assess the antimicrobial activity and to determine the zone of inhibition of coelomic fluid of some bacterial and strains. In the present study, the microbial activity was evaluated for potential antimicrobial activity against medically important bacterial strains. The antimicrobial activity of coelomic fluid was determined using agar disc diffusion method. The results showed that the remarkable inhibition of the bacterial growth was shown against the tested organisms. Hence, these coelomic fluids can be used to discover bioactive natural products that may serve as leads in the development of new pharmaceuticals research activities
\end{abstract}

Keywords: Earthworm, Coelomic fluid, Antibacterial activity, Zone of Inhibition.

\section{INTRODUCTION}

Antimicrobial agents are essentially important in reducing the global burden of infectious diseases. However, as resistant pathogens develop and spread, the effectiveness of the antibiotics is diminished. This type of bacterial resistance to the antimicrobial agents poses a very serious threat to public health, and for all kinds of antibiotics, including the major last-resort drugs, the frequencies of resistance are increasing worldwide. Therefore, alternative antimicrobial strategies are need urgently and this situation has led to a reevaluation of the therapeutic use of ancient remedies.

Earthworms belong to the phylum Annelida class oligochaetea and evolved in last Precambrian period. Earthworms are nocturnal soft-bodied saprotropic invertebrates of agro ecosystem and also one of the major macro fauna of the soil. They occupy a very unique position in the Animal kingdom and that have successfully invaded the terrestrial habitats. The body of earthworm is divided into a serious of uniformly placed segments (annuli). This nature of division of the body both externally and internally has enabled animal to have flexibility and for the initiation of development of good musculature. Earthworms are the first group of animals to have complete digestive system, closed circulatory system with haemoglobin in the plasma as carrier of oxygen and carbon di oxide with a true coelom of mesenchymal origin. Earthworms contain high levels of protein and essential amino acids. It has been proved in feeding trials that earthworm protein is worthy of being exploited as a new animal protein source, which has led to earthworm production on an industrial scale in many developed countries.

The novel antimicrobial short peptide was purified from earthworm (Eisenia fetida) by a fivestep protocol including ammonium sulfate precipitation, ultra filtration, DE-52 ion exchange chromatography, Sephadex G-10 column chromatography, and C-18 reversed-phase HPLC techniques. The purified peptide was applied to the MALDI-TOP MS to determine the molecular mass and was also subjected to TOF MS-MS analysis to determine the amino acid sequence. As a result a novel antibacterial peptide, named OEP 3121 was obtained with the molecular mars at $5108 \mathrm{Da}$ and the sequence being ACSAG. The immune system is increasingly being studied from comparative perspectives. The analysis at the immune defense system of invertebrates, such as fruit flies and earthworms, is an important effort and these systems are innate, natural non-specific, nonanticipatory and non-clonal. This is in contrast to the macrophage $\mathrm{T}$ and $\mathrm{B}$ systems that characterize vertebrate adaptive immunity whose properties can be categorized as adaptive, induced specific and anticipatory Cooper et al. (2002). In this chapter, we will focus on the earthworm system. Earthworms, like other complex invertebrates, possess several leukocyte types and synthesize and secrete a variety at immuno protective molecule.

The coelomic cavity is metameric and the segments are separated by transversal septa. Regulated transport of the coelomic fluid and coelomocytes between neighboring segments is 
ensured by channels comprised of sphincters within the septa. Each segment of the coelomic cavity is opened to the outer environment by paired nephridia and by one dorsal pore through which 9soluble metabolites and corpuscular materials can be excreted or expelled. The coelomic fluid is generally secreted by the earthworm for maintaining the moisture and to help in its physiological

activities including respiration and burrowing. However, the animal was facilitated to secrete this fluid by giving external stimuli like rise or drop in temperature or by applying external voltage. There are a number of reports for the collection of coelomic fluid by applying electric stimulation or by cold shock method.

\section{MATERIALS AND METHODS}

\subsection{Sample collection}

Earthworms were collected from the soil of different habitats by digging and hand sorting method and identified. Coelomic fluid can be directly collected from the body cavity of earthworms without causing any harm to them. In this method of collecting the coelomic fluid, five to six earthworms are taken in an approximately $10 \mathrm{~cm}$ diameter Petri plate and holding the plates in a slanting position and keep earthworms pointing downwards. Cold shock is given to earthworm by gently moving a small beaker containing a few ice cubes. The coelomic fluid released due to cold shock drips and gets collected at the lower side of the Petri plate. This fluid can be pipette out using a sterilized pipette with fine nozzle. This is the pure coelomic fluid that can be used for different biological investigations.

\subsection{Antibacterial activity}

Antibacterial potential of the precipitated protein, from earthworm coelomic fluid was used to elucidate the activity by agar well diffusion method

\section{RESULTS}

\subsection{Antibacterial activity}

The antibacterial activity of the sample was checked against gram positive and gram-negative bacteria and it was found that it had a vast range of activity against those human pathogens (Fig. 1). The Zone of inhibition against different human pathogens was listed in Table 1 . The present work is supposed to be the first extensive work in antimicrobial activity of Indian earthworm species. To test the antimicrobial activity of coelomic fluid, the inhibition zone formation around the coelomic fluid was noted and measured the diameter of that inhibition zone range. The antimicrobial activity of earthworm coelomic fluid, Drawida scandens and Drawida sulcata were confined against disease causing microorganism namely, Vibrio para haemolyticus and Bacillus subtillus through the range of inhibition zone formation.

\begin{tabular}{lcc}
$\begin{array}{c}\text { Name of the } \\
\text { species }\end{array}$ & $\begin{array}{c}\text { Vibriopara } \\
\text { haemolyticus }\end{array}$ & $\begin{array}{c}\text { Baciltus } \\
\text { subtillus }\end{array}$ \\
\hline $\begin{array}{l}\text { Drawida } \\
\text { scandens }\end{array}$ & $0.3 \mathrm{~cm}$ & $1.6 \mathrm{~cm}$ \\
$\begin{array}{l}\text { Drawida } \\
\text { sulcata }\end{array}$ & $0.5 \mathrm{~cm}$ & $0.8 \mathrm{~cm}$ \\
\hline
\end{tabular}

The antimicrobial activity of earthworm coelomic fluid Drawida scandens and Drawida sulcata were confined through the inhibition zone formation ranging at range $0.3-1.6 \mathrm{~cm}$ and $0.5-0.8$ $\mathrm{cm}$ respectively. The antimicrobial activity in the coelomic fluid of earthworm may be because of innate immune mechanism and detect microorganism by recognizing conserved molecular pattern.

\section{Fig 1. Collection of earthworm Coelomic fluid}

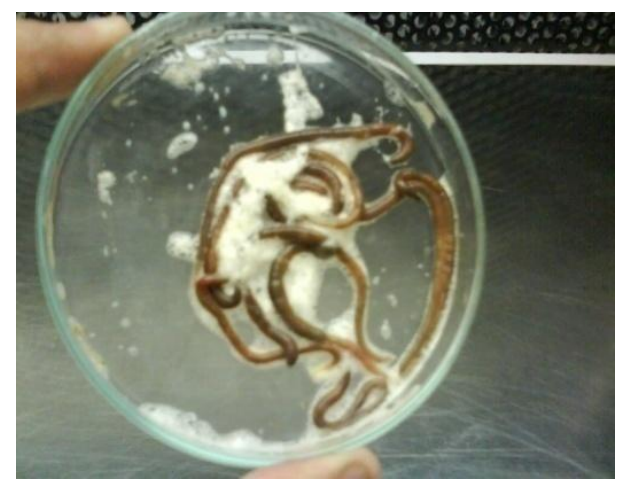

\section{DISCUSSION}

During the 700 million years of their existence, EWs have evolved in the environment replete with microorganisms, some of which threaten their existence, therefore they have developed efficient defense mechanisms against invading microorganisms. There is a variety of relationships between EW and microbes: (1) microbe as food for earthworm, (2) microbes as nutritive material for growth and reproduction, (3) microbes-mostly Gram positive, pathogenic are digested by EW and thereby facilitate multiplication of useful microbes in the gut and (5) microbes are distributed to new places in soil.

The molecules which defend the EWs from microbes have been detected in the celomic fluid of Lumbricus and Eisenia. This activity is attributed to 
some proteins, such as lysozyme and fetidins . Few reports are also available regarding antimicrobial agents from EWs tissue.

Several bioactive proteins have been found in the coelomic fluid of earthworms. These proteins exhibit a variety of antibacterial, hemolytic, cytotoxic, hemagglutinating; and proteolytic activities, and the biological and chemical nature of the compounds responsible for such activities has been studied extensively, for more than 2 decades .

Current researches in many countries on the identification, isolation and synthesis of some 'bioactive compounds' from earthworms with potential medicinal values have brought revolution in the vermiculture studies (Cooper et al., 1999; Cho et al., 2004). It has been found that coelomic fluid of the earthworms contains more than 40 proteins and exhibits several biological activities including cytolysis, proteolysis, antimicrobial, hemolysis, hemagglutination, tumorolysis and mitogenic (Cooper et al., 2002). Earthworm coelomic fluid contains biologically active molecules and leukocytes that participate in phagocytosis, encapsulation and killing of HeLa, HEp-2, PC-12 and PA317 cells in vitro. The earthworm first line of defense also consists of various substances which are synthesized and secreted along with the coelomic fluid. These substances include lysozymes, agglutinins and fetidins which can affect mitogenesis as well as induce agglutination and lysis of bacteria.

The first haemolytic proteins were named Eisenia fetida andrei factors and characterized as two glycoproteins secreted by chloragocytes and eleocytes (Balamurugan, 2007). A protein of molecular weight, $42 \mathrm{kDa}$ namely, coelomic cytolytic factor was identified from Eisenia fetida. It is involved in the activation of pro-phenol oxidase cascade via recognition of Gram-negative bacterial cell wall molecules, such as glucan and lipopolysaccharide. Fetidins are potentially interesting hemolytic and antibacterial proteins secreted by chloragocytes of annelids. The fetidin system, which was originally described as a hemolytic factor, consists of two distinct glycosylated proteins of $40 \mathrm{kDa}$ and $45 \mathrm{kDa}$. The fetidins of Eisenia fetida are responsible for cytolysis, antibacterial reaction and clotting. Another protein of molecular weight $38 \mathrm{kDa}$ referred to as Eiseniapore, was isolated from Eisenia fetida and it exhibited a strong lytic activity against erythrocytes.

The Earthworm (phylum Annelida) is one of the first organisms in the evolution that possess immunological recognition and memory. The EWs like the other complex invertebrates produce several types of leukocytes and synthesize and secrete the variety of immune-protective molecules. They possess innate immunity, as well as some functions associated with the adaptive immunity Cooper et al., 1999). The celomocytes involved in innate immunity, play a central role in the earthworm immune system (phagocytosis, releasing of lytic factors. The earthworm celomocyte cells also provide immune functions and possess several CD markers (CD11, CD24, CD45RA, CD45R0, CD49b, CD54 and CD90)

associated with innate immunity. Immunoprotective molecules synthesized and secreted from celomocytes induce agglutination, opsonisation and lysis of foreign material.

The studies of different authors have also indicated that the coelomic fluid of earthworm exhibits other biological functions, including bacteriostatic, proteolytic, cytolytic (hemolytic), mitogen activity and antitumor activity against the human hepatoma cells in vitro and in vivo (Chen et al., 2007; Bilej et al., 1995; Chen et al., 2001.

\section{REFERENCES}

Balamurugan, M., K. Parthasarathi, E.L. Cooper and L.S. Ranganathan (2007). Earthworm paste (Lampito mauritii Kinberg) alters inflammatory, oxidative, hematological and serum biochemical indices of inflamed rat. Eur. Rev. Med. Pharmacol. Sci., 11: 7790.

Bilej, M., L. Brys, A. Beschin, R. Lucas, E. Vercauteren and R. Hanušová, (1995). Identification of a cytolytic protein in the coelomic fluid of Eisenia foetida earthworms. Immunol. Lett., 45: 123-128.

Chen, H. (2001). Anti-tumor effect of earthworm extracts EE2. Chin. Clin. Oncol., 6: 349-350.

Chen, H., S. Takahashi, M. Imamura, E. Okutani, Z. Zhang and K. Chayama, (2007). Earthworm fibrinolytic enzyme: anti-tumor activity on human hepatoma cells in vitro and in vivo. Chin. Med. J., 120: 898904.

Cho, J.H., E.S. Choi, H.G. Lim and H.H. Lee, (2004). Purification and characterization of six fibrinolitic serine-proteases from earthworm Lumbricus rubellus. J. Biochem. Mol. Biol., 37: 199-205.

Cooper, E.L., A. Cossarizza, E. Kauschke and C. Franceschi, (1999). Cell adhesion and the immune system: case study using earthworms. Micro. Res. Techn., 44: 237-253.

Cooper, E.L., E. Kauschke and A. Cossariazza, (2002). Digging for innate immunity since Darwin and Metchnikoff. Bio Essays,24: 319-333. 